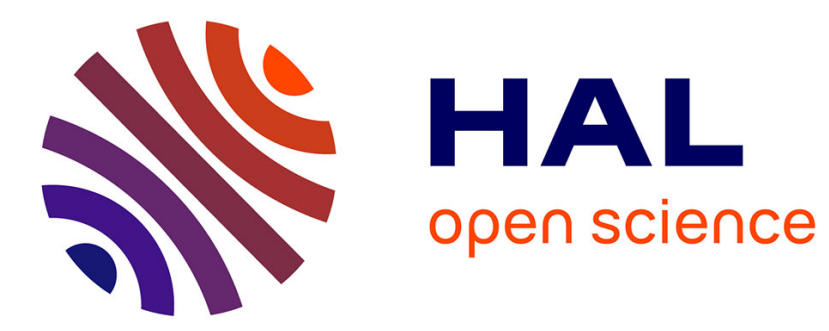

\title{
Identification of Allergens in Complex Mixtures and Products
}

\author{
Elena Gimenez-Arnau
}

\section{To cite this version:}

Elena Gimenez-Arnau. Identification of Allergens in Complex Mixtures and Products. Jeanne Duus Johansen; Vera Mahler; Jean-Pierre Lepoittevin; Peter J. Frosch. Contact Dermatitis, Springer, pp.114, 2019, 978-3-319-72451-5. 10.1007/978-3-319-72451-5_5-1. hal-02979657

\section{HAL Id: hal-02979657 \\ https://hal.science/hal-02979657}

Submitted on 27 Oct 2020

HAL is a multi-disciplinary open access archive for the deposit and dissemination of scientific research documents, whether they are published or not. The documents may come from teaching and research institutions in France or abroad, or from public or private research centers.
L'archive ouverte pluridisciplinaire HAL, est destinée au dépôt et à la diffusion de documents scientifiques de niveau recherche, publiés ou non, émanant des établissements d'enseignement et de recherche français ou étrangers, des laboratoires publics ou privés. 


\section{Metadata of the chapter that will be visualized online}

\begin{tabular}{lll}
\hline Chapter Title & Identification of Allergens in Complex Mixtures and Products \\
\hline Copyright Year & 2019 & \\
\hline Copyright Holder & Springer Nature Switzerland AG & \\
\hline Corresponding Author & $\begin{array}{l}\text { Family Name } \\
\text { Particle }\end{array}$ & Giménez-Arnau \\
& Given Name & Elena \\
& Suffix & \\
& Division/Department & Dermatochemistry Laboratory \\
& Organization/University & University of Strasbourg-Institut de \\
& Chimi@istitut le Bel \\
& City & Strasbourg \\
Country & France \\
Email & egimenez@unistra.fr
\end{tabular}

Abstract

Identifying contact allergens among the myriad of chemicals used in commercial products is an extremely arduous task. This is even more difficult in the case of components of complex mixtures such as natural extracts and essential oils. Today, non-animal alternative methods validated to assess the sensitizing potential of chemicals are, overall, unable to completely predict the skin sensitization potential of these complex mixtures of chemicals. Moreover, toxicological profiles are very difficult to extrapolate from the mere sum of the profiles of the individual constituents as required today. In this context, hazard identification remains still one of the best solutions for risk assessment. This chapter presents a brief overview of methods allowing the identification of allergens in complicated chemical mixtures, going from bioassay-guided fractionation and combination with structure-activity relationships studies to more recent new techniques developed to trap and identify reactive intermediates in natural extracts during air oxidation. Practical applications are exposed such as the case of oak moss absolute. Also, the assessment of the sensitization potential of tea tree oil is a typical example of the challenges that toxicologists encounter in the safety evaluation of essential oils. Methods based on chemical reactivity and fluorescence trapping, basically studying the oil after aging and air oxidation, are discussed. Hence, a great deal of progress has been accomplished during the last years for the identification of chemicals culprit of the sensitizing potential of very complex chemical mixtures. That being said, the identification of allergens in complex mixtures and products is still a challenging puzzle.

Keywords

(separated by "-")
Bioassay-guided fractionation - Structure-activity relationships - In chemico methods - Fluorescence trapping - Chemical reactivity - Oak moss absolute - Tea tree oil 


\title{
Author's Proof
}

\section{Identification of Allergens in Complex Mixtures and Products}

\author{
Elena Giménez-Arnau
}

\section{Contents}

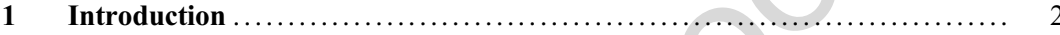

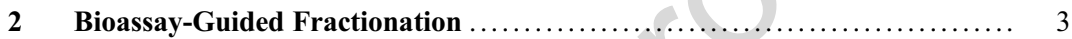

3 Bioassay-Guided Fractionation Combined with SARs $\ldots \ldots \ldots \ldots \ldots \ldots \ldots \ldots$

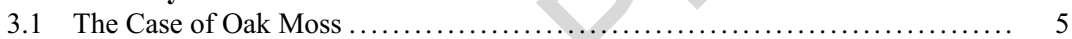

$4 \quad$ In Chemico Methods Based on Chemical Reactivity ................... 8

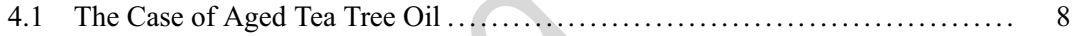

4.2 The Case of a Chamomile Plant Extract: Combination with Bio-guided Fractionation Using In Vitro Assays .............................. 10

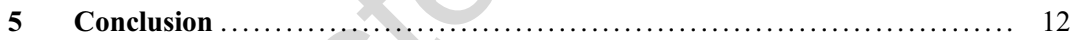

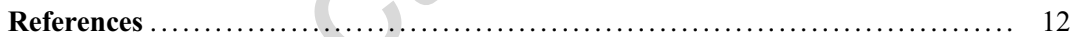

\begin{abstract}
Identifying contact allergens among the myriad of chemicals used in commercial products is an extremely arduous task. This is even more difficult in the case of components of complex mixtures such as natural extracts and essential oils. Today, non-animal alternative methods validated to assess the sensitizing potential of chemicals are, overall, unable to completely predict the skin sensitization potential of these complex mixtures of chemicals. Moreover, toxicological profiles are very difficult to extrapolate from the mere sum of the profiles of the individual constituents as required today. In
\end{abstract}

\section{E. Giménez-Arnau $(\bowtie)$}

Dermatochemistry Laboratory, University of Strasbourg-

e-mail: egimenez@unistra.fr

this context, hazard identification remains still 27 one of the best solutions for risk assessment. 28 This chapter presents a brief overview of 29 methods allowing the identification of aller- 30 gens in complicated chemical mixtures, going 31 from bioassay-guided fractionation and com- 32 bination with structure-activity relationships 33 studies to more recent new techniques devel- 34 oped to trap and identify reactive intermediates 35 in natural extracts during air oxidation. Practi- 36 cal applications are exposed such as the case of 37 oak moss absolute. Also, the assessment of the 38 sensitization potential of tea tree oil is a typical 39 example of the challenges that toxicologists 40 encounter in the safety evaluation of essential 41 oils. Methods based on chemical reactivity and 42 fluorescence trapping, basically studying the 43 oil after aging and air oxidation, are discussed. 44 


\section{Author's Proof}

Hence, a great deal of progress has been accomplished during the last years for the identification of chemicals culprit of the sensitizing potential of very complex chemical mixtures. That being said, the identification of allergens in complex mixtures and products is still a challenging puzzle.

\section{Keywords}

Bioassay-guided fractionation - Structureactivity relationships - In chemico methods · Fluorescence trapping - Chemical reactivity · Oak moss absolute $\cdot$ Tea tree oil

\section{Introduction}

Preventive measures are mandatory in the management of allergic contact dermatitis to a chemical. The first essential preventive step is hazard identification, in other words, to fully identify the nature of chemicals responsible for causing contact allergy in the consumer. It is then possible to create initiatives that regulate exposure to that chemical so that induction of skin sensitization does not take place and to improve risk assessment procedures. This confirms the necessity to have suitable, sensitive, and reliable methods for the prospective identification of novel chemicals that possess the potential to cause sensitization of the skin.

Identifying contact allergens among the myriad of chemicals used in commercial products can be an extremely arduous task. For instance, approximately 3000 fragrance ingredients, of synthetic or natural origin, are currently available to the perfumer for compounding a fragrance formula [1]. Thus, a single perfume or fragrance composition may consist of 10-300 different ingredients. And among them are natural extracts and essential oils. Essential oils are complex volatile odorous mixtures of terpenes, aldehydes, alcohols, esters, and ketones, widely used in aromatherapy (massaging, adding to bath, inhalers, etc.) and in the perfume and cosmetic industry. Because of their constant use, contact allergy has been increasingly recognized [2].
Assessment of the skin sensitization potential of 88 chemical compounds, another essential toxicologi- 89 cal end-point in safety evaluation measures, has 90 made a great deal of progress during the last decade 91 due to the encouragement of regulatory agencies to 92 develop alternative methods to eliminate the use of 93 animals [3, 4]. Several in silico, in vitro, and in 94 chemico alternative methods have been developed 95 to assess skin sensitization to chemicals following 96 the ban on animal testing introduced by cosmetic 97 legislation in Europe in 2013. Some of these 98 methods, such as the in chemico direct peptide 99 reactivity assay (DPRA), the in vitro ARE-Nrf2 100 luciferase assay (KeratinoSens ${ }^{\mathrm{TM}}$ ), and the human 101 cell line activation test (h-CLAT), have been 102 recently adopted by the Organization for Economic 103 Co-operation and Development (OECD) for testing 104 health effects of chemicals [5-7]. These tests were 105 developed and validated for the testing of pure sub- 106 stances. However, REACH regulation requires not 107 only pure substances to be registered but also regis- 108 tration of mixtures extracted from natural sources. 109 Though, there is very little experience with testing 110 of mixtures, and assessment of test material with 111 more than one component has been proved to be an 112 elusive task in existing methods. The in vivo local 113 lymph node assay (LLNA) was used nevertheless to 114 test a number of essential oils and authors stated that 115 in general the potency of each essential oil did not 116 differ significantly from that of its main individual 117 components [8]. Also, the applicability of the 118 KeratinoSens $^{\mathrm{TM}}$ assay has been evaluated as a 119 proof of concept for four plant extracts used in 120 cosmetics, spiked with different doses of citral, 121 cinnamaldehyde, and isoeugenol [9]. The extracts 122 were negative in the test, whereas they were positive 123 when spiked with the sensitizers. Finally, hapten- 124 peptide reactivity-based DPRA was evaluated 125 in a very preliminary approach to evaluate at a first 126 sight chemical reactivity of mixtures. Two binary 127 combinations of fragrance aldehydes were studied, 128 hydroxycitronellal-citral/citral-cinnamaldehyde. 129 Their reactivity towards DPRA peptides was 130 compared with that of the single constituents. 131 In general, the chemical described as the most 132 potent sensitizer was driving the reactivity in the 133 mixtures. Therefore, it could be hypothesized 134 


\section{Author's Proof}

that the DPRA would estimate the mixture chemical reactivity similar to that of the stronger sensitizer component [10]. Though, even if efforts continue to be done, each of the above non-animal alternative methods are, overall, still unable to completely predict the skin sensitization potential of complex mixtures of chemicals. In this context, hazard identification remains still one of the best solutions for risk assessment.

The present chapter describes different methodologies that exist today for the identification of contact allergens in complex mixtures and products, such as the use of bioassay-guided chemical fractionation, in combination with structureactivity relationships studies (SARs) and new techniques developed to trap and identify reactive intermediates in natural extracts during air oxidation. Practical applications such as eau de toilette cases, the allergenic natural extract oak moss, and sensitizing air oxidized tea tree oil are exposed.

Bioassay-Guided Fractionation

Bioassay-guided fractionation is a common used strategy for the identification of bioactive compounds and new drugs $[11,12]$. It is based on the isolation of a pure chemical agent of natural origin by a step-by-step separation of extracted components upon differences in their physicochemical properties and assessing the biological activity, followed by a next round of separation and assaying. Typically, the process is initiated after a given crude, normally prepared by solvent extraction of the natural material, is considered to be "active" in a specific in vitro assay. The end-goal is the identification of compounds responsible for the observed in vitro activity. The way to that end is rather simple. After fractionating the crude extract, normally by chromatographic techniques such as column chromatography and high-performance liquid chromatography, fractions generated are tested in the in vitro assay. These steps are then repeated with active fractions until pure, active compounds are obtained for which the structure can be determined by using spectroscopic methods such as nuclear magnetic resonance (NMR) and 179 mass spectrometry (MS).

The same kind of methodology can be applied 181 to allergenic perfume mixtures in order to find the 182 compound(s) responsible for skin sensitivity 183 declared by the patient(s) to that mixture. Ideally, 184 the perfume mixture is chemically fractionated, 185 and fractions obtained are tested on the patient(s) 186 by patch testing and/or by repeated open applica- 187 tion test (ROAT). Fractions giving a positive reac- 188 tion are refractionated, and the new fractions 189 obtained are tested on the patient(s). These steps 190 are repeated until a positive fraction that contains 191 one or two single compounds easily identifiable by 192 spectroscopic techniques is obtained (Fig. 1a). An 193 example can be given by a study in which the 194 offending allergen in a patient sensitive to an eau 195 de toilette but negative to the fragrance mix I (FMI) 196 was identified [13]. A 44-year-old woman without 197 previous skin problems developed an axillary rash 198 using a perfumed deodorant. At the same time, she 199 started to use the eau de toilette of the same brand 200 and developed a rash on the neck and trunk. She 201 was patch tested positive to the deodorant and the 202 eau de toilette but was negative to FMI. The eau de 203 toilette perfume concentrate was chemically frac- 204 tionated by column chromatography on silica gel 205 giving three fractions that were tested on the patient 206 in a ROAT using ethanol as vehicle. The test mate- 207 rial concentration was calculated so that it 208 corresponded to the amount of the fraction present 209 in the final formulation. Only one fraction gave a 210 positive reaction and was further chemically frac- 211 tionated to afford four subfractions that were tested 212 on the patient. One subfraction confirmed a posi- 213 tive reaction. It was analyzed and found to contain 214 simply coumarin and ethyl vanillin. The patient 215 was negative on use testing to $1 \%$ ethyl vanillin 216 in ethanol but was positive to 1\% coumarin in 217 ethanol after 2 days of application. This simple 218 case of bioassay-guided fractionation on a fra- 219 grance mixture confirmed coumarin as the 220 offending allergen. Today, coumarin, a widely 221 used fragrance compound, is one of the ingredients 222 of FMII introduced last decade as an additional 223 screening tool to FMI $[14,15]$. 224

In the case of essential oils, analytical investi- 225 gations on the components that are at the origin of 226 


\section{Author's Proof}

\section{a}

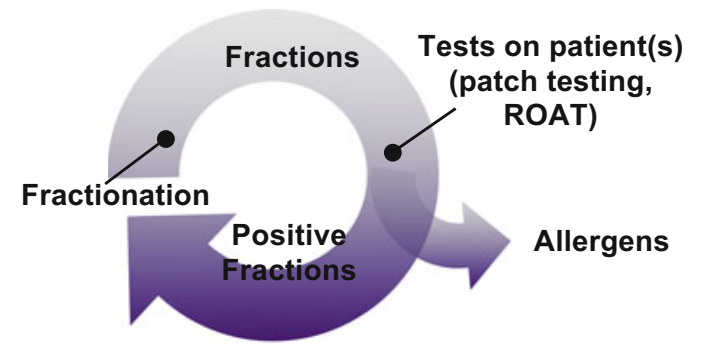

Fig. 1 Identification of allergens in complex mixtures. (a) Bioassay-guided fractionation. The mixture is chemically fractionated, and fractions obtained are tested on the patient(s) by patch testing and/or repeated open application test (ROAT). Fractions giving a positive reaction are refractionated and the new fractions obtained tested on the patient(s). These steps are repeated until a positive fraction that contains the allergen(s) is obtained. (b) allergic contact dermatitis can be carried out. This is especially useful when patients also react to individual fragrance chemicals. The analysis can show the presence or absence of such chemicals in the oils. Gas chromatography-mass spectrometry (GC-MS) is an appropriate useful tool used to elucidate allergies to essential oils as they are volatile odorous mixtures of organic compounds. A very extensive analytical investigation by GC-MS has been reported on several essential oils used by aroma therapists who reacted to many of these oils [16]. One patient was also allergic to geraniol, linalool, linalyl acetate, and $\alpha$-pinene and the other to geraniol, caryophyllene, and $\alpha$-pinene. $\alpha$-Pinene was present in 42 oil samples, linalool in 22, geraniol in 16, and caryophyllene in 37 . Concentrations of these chemicals ranged in between 1 and $10 \%(\mathrm{v} / \mathrm{v})$ in some oils and in few others $>10 \%$. Another example is the case of a patient that became sensitized from topical application of tea tree oil for therapeutic reasons [17]. GC-MS analysis identified the presence, among many other compounds, of 1,8-cineole, being the patient also positive to this compound.

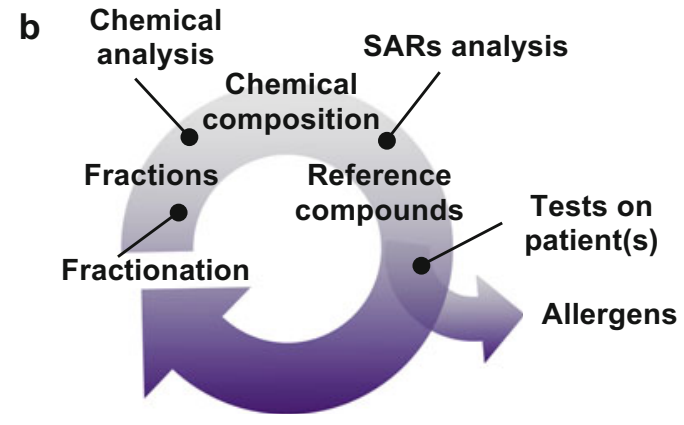

Bioassay-guided fractionation combined with structureactivity relationship analysis (SARs). The mixture is chemically fractionated and the chemical composition of the fractions analyzed. Potential allergens among the myriad of compounds composing the fractions are selected by SARs analysis as reference compounds and tested on the patient(s) in order to determine the culprit(s)

\section{Bioassay-Guided Fractionation 251 Combined with SARs 252}

The principle behind structure-activity relation- 253 ships (SARs) is that properties of a chemical, 254 with respect to its mode of interaction with a 255 defined system, are inherent in its molecular struc- 256 ture. SARs are developed by looking for links 257 between structure and biological activity, based 258 on mechanistic or empirical grounds. In other 259 words, the biological activity of a compound is 260 seen as a function of the structural and physico- 261 chemical properties of the chemical.

Progress in the understanding of the molecular 263 basis of allergic contact dermatitis has helped the 264 development of SARs for sensitizing chemicals. 265 The first step in the induction of contact allergy to 266 a chemical is the formation of a covalent, irrevers- 267 ible, bond between the sensitizer and skin proteins 268 to form an antigenic complex. This occurs princi- 269 pally through a nucleophile-electrophile mecha- 270 nism, as the majority of allergens contain in their 271 chemical structure an electrophilic functional 272 group able to react with nucleophilic amino 273 


\section{Author's Proof}

acids in proteins [18]. It can also occur in some cases through radical mechanisms [19]. It is therefore reasonable to conclude that if a chemical is capable of reacting with a protein, either directly or after a metabolism (prohaptens) or oxidation step (prehaptens), then it has the potential to be a contact allergen. Nowadays there is considerable knowledge on the chemical functions present in

Table 1 Examples of "structural alerts" present in sensitizing compounds

\begin{tabular}{|c|c|c|}
\hline $\begin{array}{l}\text { Chemical } \\
\text { function }\end{array}$ & Substituents & Structure \\
\hline Aldehydes & $\begin{array}{l}\mathrm{R}=\text { alkyl, } \\
\text { aryl }\end{array}$ & \\
\hline Ketones & $\begin{array}{l}\mathrm{R}, \mathrm{R}^{1}= \\
\text { alkyl, aryl }\end{array}$ & \\
\hline $\begin{array}{l}\text { Aldehydes, } \\
\text { amides, esters, } \\
\text { and } \\
\alpha, \beta \text {-unsaturated } \\
\text { ketones }\end{array}$ & $\begin{array}{l}\mathrm{R}=\mathrm{H}, \mathrm{C}, \mathrm{N}, \\
\mathrm{O} \text { (not } \mathrm{OH} \text { ) } \\
\mathrm{R}^{1}=\text { not } \\
\text { heteroatoms, } \\
\text { esters, } \\
\text { ketones } \\
\mathrm{R}^{2}=\text { not aryl } \\
\text { except when } \\
\mathrm{R}=\mathrm{H}\end{array}$ & \\
\hline Phenyl esters & $\begin{array}{l}\mathrm{R}=\text { alkyl } \\
\text { aryl } \\
\mathrm{R}^{1}=\text { any }\end{array}$ & \\
\hline $\begin{array}{l}\text { Hydroquinones } \\
\text { and their } O \text {-alkyl } \\
\text { precursors }\end{array}$ & $\begin{array}{l}\mathrm{R}=\mathrm{H}, \text { alkyl } \\
\mathrm{R}^{1}=\text { any }\end{array}$ & \\
\hline $\begin{array}{l}\text { Catechols and } \\
\text { their } O \text {-alkyl } \\
\text { precursors }\end{array}$ & $\begin{array}{l}\mathrm{R}=\mathrm{H}, \text { alkyl } \\
\mathrm{R}^{1}=\text { any }\end{array}$ & \\
\hline Anhydrides & $\mathrm{R}=$ any & \\
\hline $\begin{array}{l}\text { Aromatic } \\
\text { primary and } \\
\text { secondary } \\
\text { amines }\end{array}$ & $\begin{array}{l}\mathrm{R}=\text { alkyl, } \\
\text { aryl } \\
\mathrm{R}^{1}=\text { any }\end{array}$ & \\
\hline Alkyl halides & $\begin{array}{l}\mathrm{R}=\text { alkyl } \\
\mathrm{X}=\mathrm{Cl}, \mathrm{Br}, \mathrm{I}\end{array}$ & $R-X$ \\
\hline
\end{tabular}

chemicals that are related to a sensitizing poten- 282 tial. This knowledge, relating chemical structures 283 to skin sensitization, is decomposed in a series of 284 chemical rules, also called "structural alerts." A 285 "structural alert" consists of a total or partial 286 chemical structure known to present a risk. The 287 presence of a "structural alert" in a structure is 288 thus an indication of a capacity to modify skin 289 proteins and thus behave as a skin sensitizer. 290 Examples of "structural alerts" are shown in 291 Table 1.

In the course of investigations on fragrance 293 chemical allergy, a new approach for the identifica- 294 tion of fragrance sensitizers present in complex 295 mixtures was developed based on the combination 296 of bioassay-guided chemical fractionation, chemi- 297 cal analysis, and SARs studies. The need to develop 298 this methodology, complementing simple bioassay- 299 guided fractionation, became apparent due to the 300 difficulty to obtain more and more refined fractions 301 in the case of complex fragrance mixtures. Basi- 302 cally, the fragrance mixture is chemically fraction- 303 ated, and the fractions obtained are tested on the 304 patient(s) allergic to the mixture by patch testing 305 and/or by ROAT. Positive fractions are subjected to 306 an extensive chemical analysis (GC-MS, LC-MS) 307 in order to identify chemical composition and mol- 308 ecule structures. From the structures, a SARs anal- 309 ysis permits to select molecules with a suspected 310 sensitizing potential as defined by the presence of 311 structural alerts. These molecules (reference com- 312 pounds) are then directly tested on the patient(s) for 313 the identification of the actual sensitizer(s) (Fig. 1b). 314 The major advantage of this approach is to avoid 315 iterative fractionation/patient testing sessions that 316 are time consuming, require considerable effort by 317 the patients and the scientists involved, and very 318 often are of low benefit. A practical example is the 319 case of oak moss.

\subsection{The Case of Oak Moss}

Many natural extracts are used in the perfume indus- 322 try. Natural extracts are complex mixtures 323 containing several hundred different chemicals 324 responsible for the complexity of the odor. And 325 among them is oak moss absolute, prepared from 326 


\section{Author's Proof}

the lichen Evernia prunastri (L.) Arch. Because of its woody aroma and fixative properties, it has been extensively used in perfumery as a natural fragrance, particularly for masculine products. Oak moss is considered a major contact sensitizer. Included in FMI, it has been reported as the most common allergen among the FMI eight ingredients [20].

Oak moss absolute is prepared by extracting the harvested lichen with hydrocarbon solvents, subsequently treating of the so-called oak moss concrete with a mixture of alcohols. In the 1970s-1980s, the chemical composition of oak moss absolute was extensively studied, and the allergenic potential of the major components was evaluated $[21,22]$. At that time, sensitivity to oak moss was associated with the presence of phenylbenzoates such as atranorin and evernic acid but also with usnic acid although not a phenyl benzoate. For many years benzene was used to prepare oak moss concrete. With time it was replaced by more polar hydrocarbons. The composition of oak moss absolute did then change, and even though several potential sensitizers had been identified from former benzene extracts, constituents of oak moss absolute obtained from the new extraction procedures and the allergenic status were not clear.

Bioassay-guided fractionation combined with SARs was applied to new oak moss absolute extracts [23]. Patients with previous known sensitivity to oak moss were recruited for the study. After a first round of fractionation of the natural extract by column chromatography and patch testing, attention was focused on the strongest eliciting fraction in the patients. Chemical analysis of this fraction by GC-MS identified eight chemicals derived from a resorcinol structure. SARs analysis indicated that they all should be considered potential sensitizers. In order to avoid too many patch tests, the most representative molecules covering the different molecular structures were selected and tested on the patients. Atranol and chloroatranol were this way identified as the major eliciting chemicals and methyl- $\beta$-orcinol carboxylate as the minor one (Fig. 2a). Atranol and chloroatranol 371 are degradation products formed during oak moss 372 processing, after transesterification and decarbox- 373 ylation of atranorin and chloroatranorin during the 374 ethanolic treatment (Fig. 2b). Methyl- $\beta$-orcinol car- 375 boxylate, also obtained during this processing, is 376 essentially responsible for the characteristic earthy- 377 moss-like odor of oak moss products. $\quad 378$

The results of this study allowed the identifica- 379 tion of atranol and chloroatranol as offending 380 chemicals in oak moss absolute. It was later shown 381 that both atranol and chloroatranol elicit reactions at 382 very low levels of exposure [24]. Differences in the 383 elicitation capacity between both substances are 384 counterbalanced by exposure being greater to 385 atranol than to chloroatranol, as it has been found 386 that oak moss absolute contains approximately $2.1 \% 387$ $(\mathrm{w} / \mathrm{w})$ of atranol and $0.9 \%(\mathrm{w} / \mathrm{w})$ of chloroatranol 388 [23]. Of both compounds, chloroatranol, a hitherto 389 unknown fragrance allergen, was identified as the 390 main allergen in oak moss absolute. Further expo- 391 sure assessment together with dose-response elicita- 392 tion studies showed that chloroatranol elicited 393 reactions by repeated open exposure at the ppm 394 level $(0.0005 \%)$ and at the ppb level on patch testing 395 $(50 \%$ of patients elicited at $0.000015 \%)$ [25, 396 26]. These results were described as unprecedented. 397

As a consequence, the International Fragrance 398 Association (IFRA) standard on oak moss extracts 399 fixed the maximum concentration allowed in skin 400 contact cosmetic products to $0.1 \%$. Since 2008401 there is also an IFRA restriction on the concentra- 402 tion of atranol and chloroatranol in oak moss 403 extracts which must not exceed 100 ppm each 404 [27]. In 2004, the Scientific Committee on Con- 405 sumer Products (SCCP) recommended that 406 atranol and chloroatranol should not be present 407 in cosmetic products [28]. Sensitization data on 408 treated oak moss with removed atranol and 409 chloroatranol suggested that it was possible to 410 reduce the content of both to $<2 \mathrm{ppm}$ each. 411 Thus, a cosmetic product containing $0.1 \%$ oak 412 moss would contain so low levels of atranol/ 413 chloroatranol that the risk of sensitization of 414 


\section{Author's Proof}
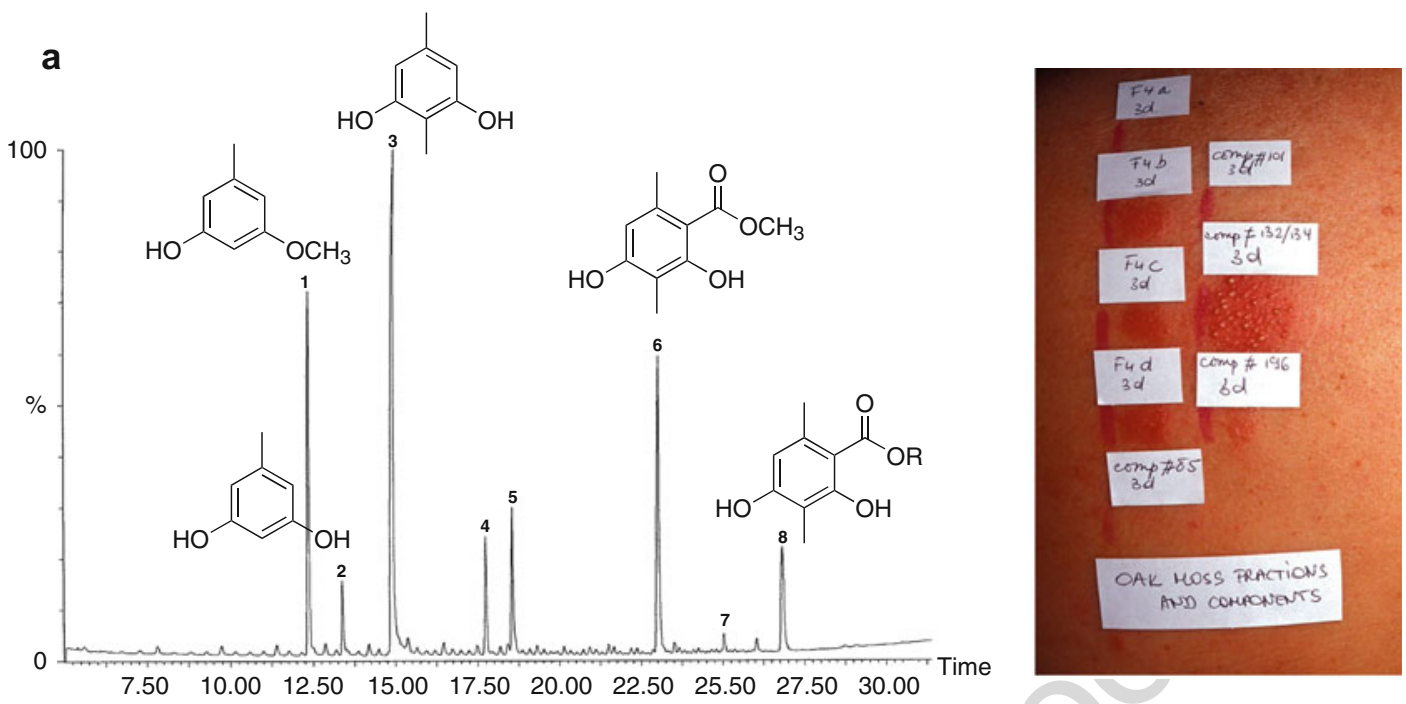<smiles>Cc1cc(O)c(C=O)c(O)c1</smiles>

b<smiles>[R]c1c(C)c(C(=O)Oc2cc(C)c(C(=O)O)c(O)c2C)c(O)c(C=O)c1O</smiles><smiles>[R]c1c(O)c(C(=O)O)c(O)c(C(=O)OCC)c1-c1ccccc1</smiles>

Atranorin: $\mathrm{R}=\mathrm{H}$ Chloroatranorin: $\mathrm{R}=\mathrm{Cl}$

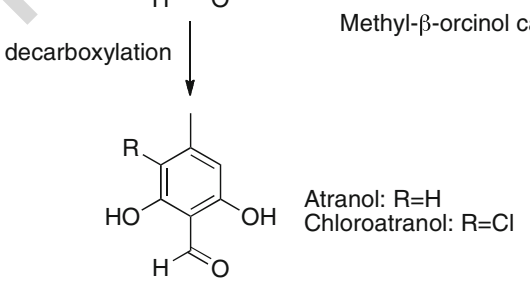

Fig. 2 Bioassay-guided fractionation-SARs study on oak moss. (a) Gas chromatogram of the strongest eliciting fraction (F4), together with chemical structures identified and patch test results of representative molecules and subfractions (courtesy $\operatorname{Pr}$ An Goossens). In the patch tests, $132 / 134$ corresponds to a mixture chloroatranol 4/atranol 5 and 196 to methyl- $\beta$-orcinol carboxylate 6 . Subfractions allergic reactions would be low. However, clinical testing was asked by the SCCP in order to demonstrate a reduction in the elicitation capacity
$\mathrm{F} 4 \mathrm{c} / \mathrm{F} 4 \mathrm{~d}$ contained atranol and chloroatranol, whereas subfraction F4b contained methyl- $\beta$-orcinol carboxylate. Subfractions patch tests results were thus in agreement with patch test results of selected molecules. (b) Formation of atranol and chloroatranol from atranorin and chloroatranorin during oak moss processing

[29]. It was shown that treated oak moss was 418 able to elicit positive reactions by patch test and 419 repeated open application test (ROAT) studies in 420 


\section{Author's Proof}

previously sensitized individuals $[30,31]$. The European Union has recently published regulation 2017/1410 finally prohibiting the use of atranol and chloroatranol in consumer products [32]. From 23 August 2019, cosmetic products containing those substances shall not be placed on the Union market, and from 23 August 2021, cosmetic products containing those substances shall not be made available on the Union market.

\section{$4 \quad$ In Chemico Methods Based on Chemical Reactivity}

Validated in chemico methods have not yet been successfully applied for the evaluation of hazardous components in complex mixtures, being this a missing component in the battery of recommended methods in risk assessment of potential skin sensitizers.

During this decade, considerable efforts have been made to improve this aspect essentially based on nuclear magnetic resonance (NMR) and fluorescence trap methods using cysteamine derivatives as model of nucleophiles in the skin. The NMR-dansyl cysteamine (NMR-DCYA) and the high-throughput screening-DCYA (HTS-DCYA) methods are in chemico approaches recently reported to assess the ability of potential skin sensitizers to covalently bind to DCYA, a model dansyl thiol. DCYA operates as surrogate of nucleophilic residues of skin proteins to study the ability of the test molecule to initiate haptenation events. The use of DCYA as nucleophilic agent enables the trapping of electrophilic and other thiol-reacting species. In the NMR-DCYA assay, the degree of electrophilic depletion over time is quantified using proton NMR techniques [33]. Thus, quantification is carried out assessing the depletion of the sensitizer, in contrast to validated methods based on the depletion of the nucleophile. Also, it is possible to have structural information and elucidate reaction mechanisms and the sensitizer site of reaction. The HTS-DCYA method enables a quick and sensitive detection of electrophilic compounds in a high-throughput screening using fluorescence assays [34]. The fluorescence thiol DCYA is incubated with the test molecule and activated to initiate a covalent binding. 465 The fluorescence response of the DCYA adducts is 466 quantified using fluorescence end-point readings. 467 The amount of reacting species is reported as a 468 reactive index (RI), which correlates with the 469 amount of DCYA adducts found after elimination 470 of unreacted DCYA. Quantification of the total fluo- 471 rescent emission can be thus used to estimate the 472 total formation of DCYA adducts or reacted species. 473 A drawback of these methods is that they only 474 consider identification of reactive electrophilic sen- 475 sitizers and do not consider sensitizers thought to 476 modify skin proteins through the intervention of 477 reactive radical intermediates [19].

\subsection{The Case of Aged Tea Tree Oil}

479

Essential oils are widely used by consumers in a 480 broad variety of goods. Because of the high fre- 481 quency of contact, essential oils and complex 482 mixtures of chemicals are common causes of con- 483 tact allergy. In a literature search, 79 essential oils 484 were found to cause positive patch test reactions 485 or allergic contact dermatitis [2]. Tea tree oil 486 (TTO), together with turpentine oil, has been one 487 of the sole essential oils for which large-scale 488 patch testing has been carried out with single 489 components. However, toxicological profiles are 490 very difficult to extrapolate from the mere sum of 491 the profiles of the individual constituents as 492 required today. The properties of the oil are deeply 493 affected by the presence and abundance of its 494 components. To add more complexity, many con- 495 stituents often undergo chemical changes over 496 time and form degradation products. For example, 497 monoterpenes are well known to form oxidized 498 by-products upon air exposure. These processes 499 usually occur via free radical mechanisms 500 forming reactive organic radicals, hydroperox- 501 ides, endoperoxides, and also electrophilic prod- 502 ucts that can themselves even degrade. 503

The assessment of the sensitization potential of 504 TTO is thus a typical example of the challenges that 505 toxicologists encounter in the safety evaluation of 506 essential oils. TTO is the volatile oil obtained by 507 steam distillation from leaves and terminal 508 


\section{Author's Proof}

branchlets of Melaleuca alternifolia, Melaleuca linariifolia, or Melaleuca dissitiflora [35]. It is a colorless to pale yellow liquid with a terpeny, coniferous, and minty-camphoraceous odor. It has been reported to have multiple biological activities such as anti-inflammatory, antitumoral, analgesic, antimicrobial, and biocidal, among others. However, of all essential oils, TTO has caused most allergic reactions since the first case reports were published in the 1990s from Australia, where the oil is produced. Still, TTO is classified as a moderate sensitizer in the local lymph node assay, chemical components lack "structural alerts" to act as skin sensitizers, and most constituents have been classified as potential pre-/ pro-haptens [36-38]. However, TTO stored in open bottles or in a bottle opened several times suffers an aging process resulting in photooxidation that leads to degradation products, which are strong sensitizers. Air exposure leads to a threefold increase in the sensitization potency of TTO. A number of different culprits have been suggested, but the identification of the real sensitizers continues to be an arduous task. The most important sensitizers in aged TTO appear to be terpinolene, ascaridole, and $\alpha$-terpinene and its oxidation products, 1,2,4trihydroxymenthane, $\alpha$-phellandrene, $d$-limonene, and myrcene. Other chemicals, albeit less frequent, are aromadendrene, $d$-carvone, $l$-carvone, terpinen4-ol, viridiflorene, sabinene, $p$-cymene, and 1,8-cineole.

Several aged "so-named" TTOs have been considered to test the applicability of the HTS-DCYA method in a recent study [39]. Initially, changes in the chemical composition of the oils after aging were analyzed by GC-MS. The aged samples showed an increase in the amount of $p$-cymene, considered as an indicative marker for aging together with the formation of numerous peroxide derivatives. For all "authentic" TTOs, a tendency of increased reactivity with increased amounts of $p$ cymene was observed, even if $p$-cymene was found to be negative and nonreactive in the HTS-DCYA assay. In parallel, those with higher peroxide content resulted in the highest reactive index (RI). The oxidized TTO sample giving the higher RI value in the HTS-DCYA assay was further analyzed by ultrahigh-performance liquid chromatography coupled with diode array detection and mass spectrometry (UHPLC-DAD-MS) in order to get 557 more information in regard to the potential reaction 558 products, the reactive species, and thus the potential 559 sensitizers. As a result, the major DCYA adducts 560 were isolated and the structures confirmed by clas- 561 sical nuclear magnetic resonance spectroscopy 562 (NMR) sequences and/or mass spectrometry. The 563 global approach of the work methodology is shown 564 in Fig. 3. Isolation of compound(s) giving the major 565 fluorescent peak demonstrated the formation of a 566 mixture of two diastereomers $(\mathrm{m} / \mathrm{z} 436)$ resulting 567 from a 1,4-Michael addition of DCYA on 568 4-hydroxy-4-methylcyclohex-2-en-1-one (Fig. 4). 569 This small electrophilic $\alpha, \beta$-unsaturated ketone of 570 $\mathrm{m} / \mathrm{z} 126$ corresponds to a reported degradation 571 by-product of ascaridole [39]. Ascaridole is an 572 endoperoxide derived from autoxidation of 573 $\alpha$-terpinene. It has been described that easy cleav- 574 age of the O-O bond leads to the loss of stable 575 isopropyl radicals through alkoxyl radical interme- 576 diates (iPr) forming this way reactive 4-hydroxy-4- 577 methylcyclohex-2-en-1-one [40]. Additional chro- 578 matographic peaks with associated $\mathrm{m} / \mathrm{z} 478$ were 579 also observed. Based on the mass fragmentation 580 pattern, adducts could have originated from iso- 581 ascaridole via the nucleophilic thiol ring opening 582 of the oxirane moiety. Indeed, isoascaridole is 583 known for a long time now as a by-product obtained 584 after decomposition of ascaridole [41]. In conclu- 585 sion, $\alpha$-terpinene may be one of the critical compo- 586 nents that undergo singlet oxygen addition to give 587 stable endoperoxides that can further form elusive 588 species such as the $\alpha, \beta$-unsaturated ketone interme- 589 diate. Presence of this kind of intermediates could 590 be responsible for the observed concomitant 591 irritancy and co-sensitization with increased con- 592 centrations of ascaridole and ascaridole-containing 593 essential oils [42].

This study thus demonstrates that formation of 595 electrophilic species via radical degradations is one 596 of the possible pathways that could explain peptide 597 reactivity and sensitization to aged TTOs. Assum- 598 ing that a lot of skin sensitizers are electrophilic 599 compounds reacting with nucleophilic amino acids 600 in the skin, this study exemplifies how the HTS- 601 DCYA assay could be used to analyze complex 602 mixtures for the presence of stable or unstable 603 


\section{Author's Proof}

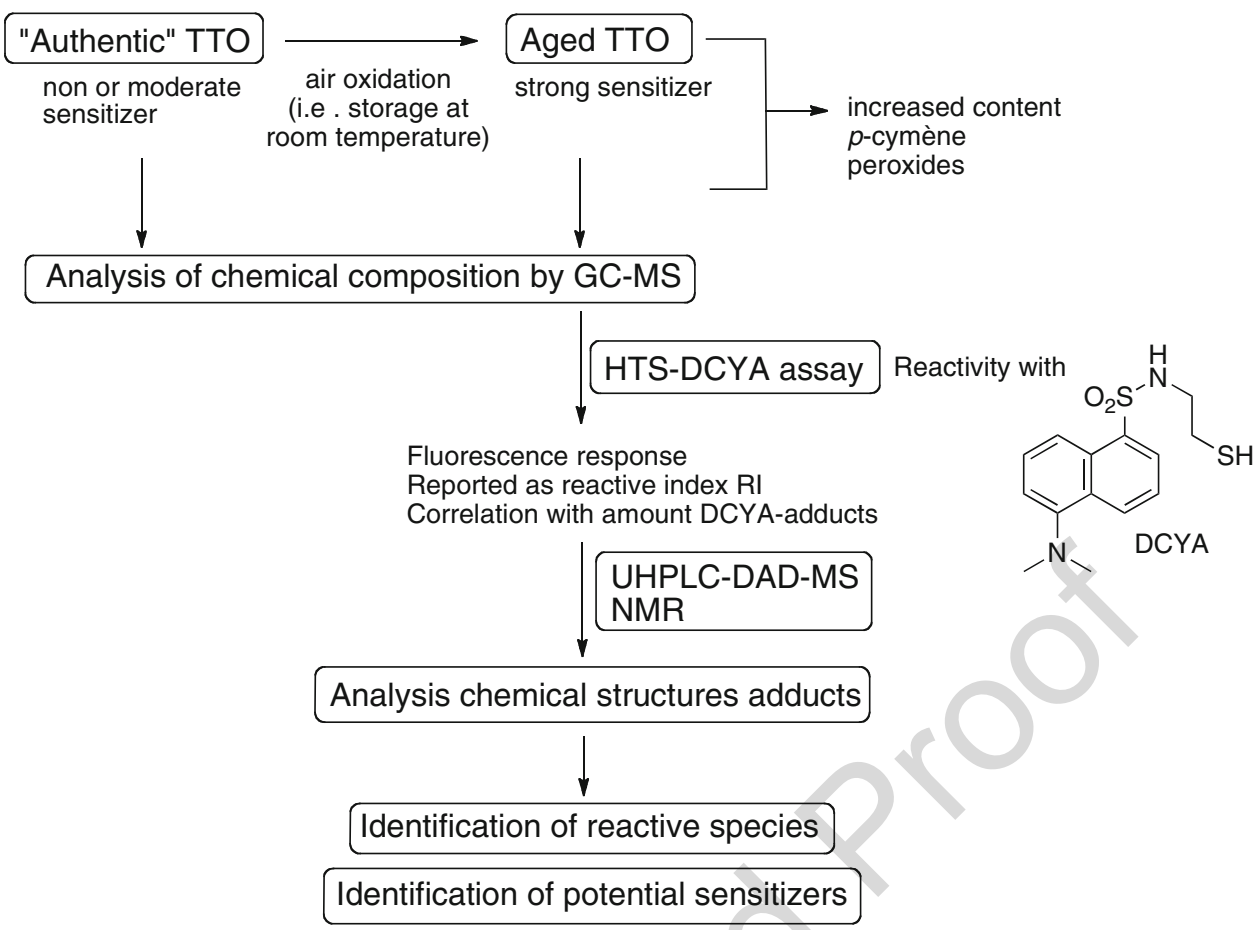

Fig. 3 Global approach for the identification of potential sensitizers in aged tea tree oil using the HTS-DCYA assay [39]

reactive electrophilic compounds as a proof of concept.

\subsection{The Case of a Chamomile Plant Extract: Combination with Bio- guided Fractionation Using In Vitro Assays}

Despite its reputation as a medicinal plant, allergic reactions to topically applied products containing chamomile extracts are frequent [43]. In a recent study, the use of in chemico methods NMR-DCYA and HTS-DCYA has been combined with bio-guided fractionation using the KeratinoSens ${ }^{\mathrm{TM}}$ assay to elucidate the culprit of the sensitizing potential of German chamomile extract (German CE) [44].

Initially, the ethanolic extract of German CE was chromatographically subfractionated. Only one of the subfractions was positive at the KeratinoSens ${ }^{\mathrm{TM}}$ assay showing luciferase induction without cytotoxicity. It was thus subsequently fractionated to isolate the major constituents to be tested for skin sensiti- 624 zation potential. Among the constituents, poly- 625 acetylene tonghaosu and cinnamic acid derivatives 626 $E$ and $Z$-glucopyranosyloxy-4-methoxycinnamic 627 acid contained structural alerts for potential 628 skin sensitization (Fig. 5). To complement the 629 KeratinoSens $^{\mathrm{TM}}$ data, the NMR-DCYA and HTS- 630 DCYA reactivity assays were then used. Surpris- 631 ingly, these compounds were only weakly reactive 632 in the HTS-DCYA assay with RI values lower to 633 the positive control cinnamaldehyde. Natural poly- 634 acetylenes are known to be potential sensitizers that 635 are unstable to air and light [45]. Similarly, 636 tonghaosu was found to quickly degrade. Thus, a 637 fraction enriched with tonghaosu was tested in the 638 HTS-DCYA assay after aging, and an increased 639 value of RI was obtained. Further, reactivity exper- 640 iments were carried out using the NMR-DCYA 641 assay. From NMR results tonghaosu was confirmed 642 to be nonreactive with DCYA, whereas the aged 643 fraction was found to contain a component clearly 644 reactive with DCYA. Purification of the aged frac- 645 tion identified this component as 1,6-dioxaspiro 646 


\section{Author's Proof}<smiles>CC1=CC=C(C(C)C(C)C(=O)OCc2ccccc2)CC1</smiles>

$\alpha$-Terpinene $\quad$-Cymene

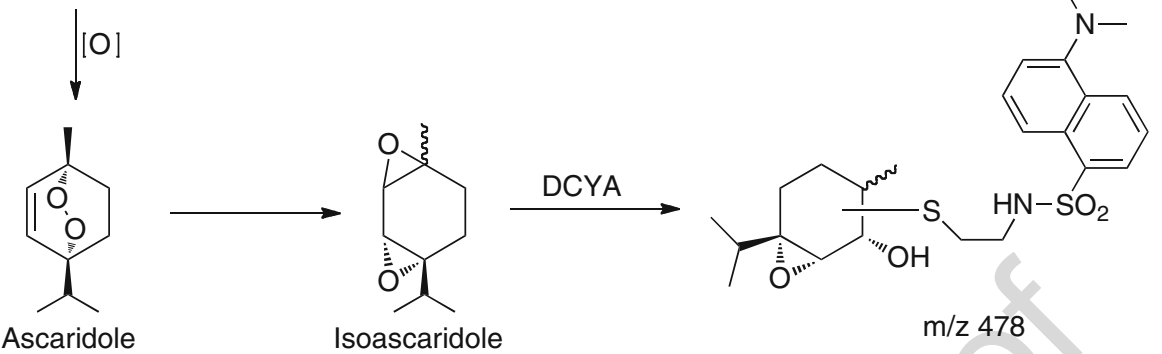

Ascaridole Isoascaridole

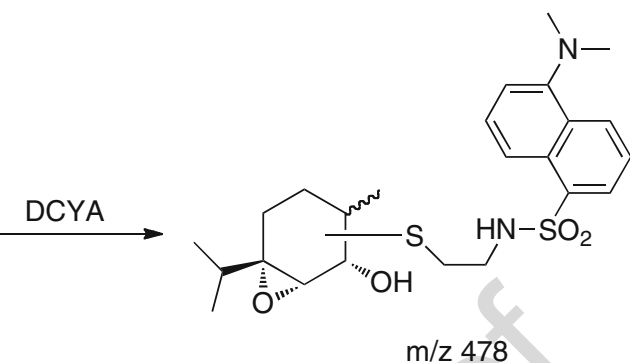

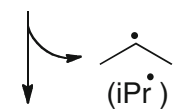<smiles>C[C@]1(O)C=CC(=O)CC1</smiles><smiles>CN(C)c1cccc2c(S(=O)(=O)NCCS[C@H]3CC(=O)CC[C@@]3(C)O)cccc12</smiles>

$m / z 436$

Fig. 4 Possible reaction scheme for the formation of DCYA adducts with electrophilic and thus potential sensitizing compounds present in TTO

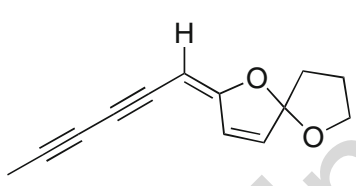

Tonghaosu<smiles>COc1ccc(/C=C/C(=O)O)c(OC2OC(CO)C(O)C(O)C2O)c1</smiles>

Glucopyranosyloxy-4-methoxycinnamic acid<smiles>CC#CC#C/C=C1\C=CC2(CCCO2)O1</smiles><smiles>CC#CC#C[C@@H]1OO[C@@]12C=CC1(CCCO1)O2</smiles>

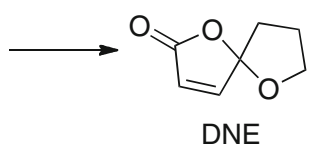

Fig. 5 Structures of isolated compounds from GermanCE and mechanism proposed for the formation of DNE from tonghaosu aging

[4.4]non-3-en-2-one (DNE) (Fig. 5). This was confirmed by comparison with a synthetically prepared sample, and its sensitization potential was further confirmed using the LLNA. From the mechanistic 650 point of view, the oxidation of tonghaosu to DNE 651 


\section{Author's Proof}

probably occurs through olefin photo-oxygenation by singlet oxygen via dioxetane formation.

Lastly, the applicability of the HTS-DCYA begins today also to be explored for the evaluation of skin sensitization of complex botanicals [46].

\section{Conclusion}

The opening step for any prevention strategy for skin sensitization is hazard identification. This stresses the necessity to have reliable methods for the prospective identification of new chemicals that possess the potential to cause skin sensitization, ideally before they are put into the market but also already present in consumer products. To complicate things, among all the ingredients present in consumer products, many are complex chemical mixtures such as essential oils or botanical natural extracts that may also have sensitizing properties. Today, the identification of chemicals culprit of the sensitizing potential of very complex chemical mixtures continues to be a puzzle even if during the last years a great deal of progress has been accomplished.

The present chapter is a brief overview of the methods existing today that allow the identification of sensitizers in those complex mixtures. Simple bioassay-guided fractionation is an established method from many years. Also, the methodology based on the combination of bioassay-guided chemical fractionation, patch test and/or use testing of individuals with fractions, detailed chemical composition analysis of positive fractions, and chemical SARs analysis of identified molecules is now a valuable tool for the identification of allergens in fragrance complex mixtures. The case of the natural extract oak moss absolute is detailed to illustrate the methodology. In addition, this last decade an important consortium of researchers are bringing new fresh air with methods based on chemical reactivity and fluorescence trapping, basically studying natural extracts after aging and air oxidation such as the example of tea tree oil. However, assessing the sensitizing potential of complex mixtures together with the identification of the culprits in the mixtures is still far from being unraveled. Moreover, following the identification of new allergens, it is critical to further conduct a complete skin sensitization risk assessment based 698 on ingredient exposure, allergenic potency, and 699 dose-response studies. The importance of expo- 700 sure, dose-response correlation, and potency esti- 701 mation has been underlined in here for the found 702 oak moss offending allergens, atranol, and 703 chloroatranol.

Still, even if lots of successful efforts have 705 been done, more are nevertheless necessary in 706 order to establish a strategy that will allow 707 assessing mixtures extracted from natural sources 708 and their active sensitizing components.

\section{References}

1. International Fragrance Association. www.ifraorg.org 711

2. de Groot AC, Schmidt E (2016) Contact allergy to 712 essential oils: general aspects. In: Essential oils. Con- 713 tact allergy and chemical composition. CRC Press, 714 Taylor \& Francis Group, Boca Raton, pp 21-38 715

3. European Commission (2003) Directive 2003/15/EC 716 of the European Parliament and of the Council of 717 27 February 2003 amending Council Directive 718 $76 / 768 / \mathrm{EEC}$ on the approximation of the laws of the 719 Member States relating to cosmetic products -7 th 720 Amendment to the European Cosmetics Directive. 721 Off J Eur Union L66: 26-35 722

4. European Commission (2006) Regulation (EC) No 723 $1907 / 2006$ of the European Parliament and of the 724 Council of the 18 December 2006 concerning the Reg- 725 istration, Evaluation, Authorisation and Restriction of 726 Chemicals (REACH), establishing a European 727 Chemicals Agency. Off J Eur Union L396: 1-849 728

5. OECD (2015) OECD guideline for the testing of 729 chemicals: In: Chemico skin sensitization: direct pep- 730 tide reactivity Assay (DPRA). OECD testing guide- 731 lines 442c. https://doi.org/10.1787/9789264229709-en 732

6. OECD (2015) OECD guideline for the testing of 733 chemicals: in vitro skin sensitization: ARE-Nrf2 lucif- 734 erase test method. OECD testing guidelines 442d. 735 https://doi.org/10.1787/9789264229822-en 736

7. OECD (2016) OECD guideline for the testing of 737 chemicals: human cell line activation test (h-CLAT). 738 OECD testing guidelines 442e. https://doi.org/10.1787/ 739 9789264264359-en

8. Api AM, Lalko J (2006) Investigation of the dermal 741 sensitization potential of various essential oils in the 742 local lymph node assay. Food Chem Toxicol 743 44:739-746. https://doi.org/10.1016/j.fct.2005.10.006 744

9. Andres E, Sá-Rocha M, Barrichello C, Haupt T, 745 Ellis G, Natsch A (2013) The sensitivity of the 746 KeratinoSens ${ }^{\mathrm{TM}}$ assay to evaluate plant extracts: a 747 pilot study. Toxicol In Vitro 27:1220-1225. https:// 748 doi.org/10.1016/j.tiv.2013.02.008 749

10. Lang M, Giménez-Arnau E, Lepoittevin JP (2017) Is it 750 possible to assess the allergenicity of mixtures based on 751 
in chemico methods? Preliminary results on common fragrance aldehydes. Flavour Fragr J 32:63-71. https:// doi.org/10.1002/ffj.3359

11. Pieters L, Vlietinck AJ (2005) Bioguided isolation of pharmacologically active plant components, still a valuable strategy for the finding of new lead compounds? J Ethnopharmacol 100:57-60. https://doi. org/10.1016/j.jep.2005.05.029

12. Houghton PJ, Raman A (1998) Laboratory handbook for the fractionation of natural extracts, 2nd edn. Springer, Berlin

13. Mutterer V, Giménez-Arnau E, Lepoittevin JP, Johansen JD, Frosch PJ, Menné T, Andersen KE, Bruze M, Rastogi SC, White IR (1999) Identification of coumarin as the sensitizer in a patient sensitive to her own perfume but negative to the fragrance mix. Contact Dermatitis 40:196-199. https://doi.org/10.1111/j.1600-0536.1999. tb06033.x

14. Frosch PJ, Pirker C, Rastogi SC, Andersen KE, Bruze M, Svedman C, Goossens A, White IR, Uter W, Giménez-Arnau E, Lepoittevin JP, Menné T, Johansen JD (2005) Patch testing with a new fragrance mix detects additional patients sensitive to perfumes and missed by the current fragrance mix. Contact Dermatitis 52:207-215. https://doi.org/10.1111/j.01051873.2005.00565.x

15. Frosch PJ, Rastogi SC, Pirker C, Brinkmeier T, Andersen KE, Bruze M, Svedman C, Goossens A, White IR, Uter W, Giménez-Arnau E, Lepoittevin JP, Johansen JD, Menné T (2005) Patch testing with a new fragrance mix - reactivity to the individual constituents and chemical detection in relevant cosmetic products. Contact Dermatitis 52:216-225. https://doi.org/10.1111/ j.0105-1873.2005.00563.x

16. Dharmagunawardena B, Takwale A, Sanders KJ, Cannan S, Rodger A, Ilchyshyn A (2002) Gas chromatography: an investigative tool in multiple allergies to essential oils. Contact Dermatitis 47:288-292. https:// doi.org/10.1034/j.1600-0536.2002.470506.x

17. de Groot AC, Weijland JW (1992) Systemic contact dermatitis from tea tree oil. Contact Dermatitis 27:279-280. https://doi.org/10.1111/j.1600-0536.1992. tb03279.x

18. Lepoittevin JP (2011) Molecular aspects in allergic and irritant contact dermatitis. In: Johansen JD, Frosch PJ, Lepoittevin JP (eds) Contact dermatitis, 5th edn. Springer, Berlin, pp 91-110

19. Kao D, Chaintreau A, Lepoittevin JP, Giménez-Arnau E (2014) Mechanistic studies on the reactivity of sensitizing allylic hydroperoxides: investigation of the covalent modification of amino acids by carbon-radical intermediates. Toxicol Res 3:278-289. https://doi.org/ $10.1039 / \mathrm{c} 3 \mathrm{tx} 50109 \mathrm{~d}$

20. Uter W, Geier J, Frosch P, Schnuch A (2010) Contact allergy to fragrances: current patch test results (2005-2008) from the Information Network of Departments of Dermatology. Contact Dermatitis 63:254-261. https://doi.org/10.1111/j.1600-0536.2010.01759.x

21. Schulz H, Albroscheit G (1989) Characterization of oak moss products used in perfumery by high-performance liquid chromatography. J Chromatogr 466:301-306. 812 https://doi.org/10.1016/S0021-9673(01)84625-2 813

22. Thune P, Solberg Y, McFadden N, Staerfelt F, 814 Sandberg M (1982) Perfume allergy due to oak moss 815 and other lichens. Contact Dermatitis 8:396-400. 816 https://doi.org/10.1111/j.1600-0536.1982.tb04265.x 817

23. Bernard G, Giménez-Arnau E, Rastogi SC, Heydorn S, 818 Johansen JD, Menné T, Goossens A, Andersen KE, 819 Lepoittevin JP (2003) Contact allergy to oak moss: 820 search for sensitizing molecules using combined 821 bioassay-guided chemical fractionation, GC-MS, and 822 structure-activity relationship analysis. Arch Dermatol 823 Res 295:229-235. https://doi.org/10.1007/s00403- 824 003-0426-3

825

24. Johansen JD, Bernard G, Giménez-Arnau E, 826 Lepoittevin JP, Bruze M, Andersen KE (2006) Com- 827 parison of elicitation potential of chloroatranol and 828 atranol-2 allergens in oak moss absolute. Contact Der- 829 matitis 54:192-195. https://doi.org/10.1111/j.0105- 830 1873.2006.00814.x 831

25. Johansen JD, Andersen KE, Svedman C, Bruze M, 832 Bernard G, Giménez-Arnau E, Rastogi SC, Lepoittevin 833 JP, Menné T (2003) Chloroatranol, an extremely potent 834 allergen hidden in perfumes: a dose-response elicita- 835 tion study. Contact Dermatitis 49:180-184. https://doi. 836 org/10.1111/j.0105-1873.2003.0214.x 837

26. Rastogi SC, Bossi R, Johansen JD, Menné T, 838 Bernard G, Giménez-Arnau E, Lepoittevin JP (2004) 839 Content of oak moss allergens atranol and 840 chloroatranol in perfumes and similar products. Con- 841 tact Dermatitis 50:367-370. https://doi.org/10.1111/ 842 j.0105-1873.2004.00379.x 843

27. International Fragrance Association (2008) Code of 844 practice 43rd amendment. Standard on oak moss 845 extracts. www.ifraorg.org 846

28. European Commission, Scientific Committee on Con- 847 sumer Products (2004) Atranol and chloroatranol pre- 848 sent in natural extracts (e.g. oak moss and tree moss 849 extract). http://ec.europa.eu/health/ph_risk/committees/ 850 04_sccp/docs/sccp_o_006.pdf

29. European Commission, Scientific Committee on Con- 852 sumer Products (2008) Opinion on oak moss/tree moss 853 (sensitisation only). http://ec.europa.eu/health/ph_ 854 risk/committees/04_sccp/docs/sccp_o_131.pdf_ 855

30. Nardelli A, Giménez-Arnau E, Bernard G, Lepoittevin 856 JP, Goossens A (2009) Is a low content in atranol/ 857 chloroatranol safe in oak moss-sensitized individuals? 858 Contact Dermatitis 60:91-95. https://doi.org/10.1111/ 859 j.1600-0536.2008.01478.x 860

31. Mowitz M, Zimerson E, Svedman C, Bruze M (2013) 861 Patch testing with serial dilutions and thin-layer chro- 862 matograms of oak moss absolutes containing high and 863 low levels of atranol and chloroatranol. Contact Der- 864 matitis 69:342-349. https://doi.org/10.1111/cod.12126 865

32. Commission Regulation (EU) (2017) 2017/1410 of 866 2 August 2017 amending Annexes II and III to Regu- 867 lation (EC) No 1223/2009 of the European Parliament 868 and on the Council on cosmetic products. Off J Eur 869 Union L202: 1-2

33. Chittiboyina AG, Avonto C, Rua D, Khan IA (2015) 871 Alternative testing methods for skin sensitization: 872 


\section{Author's Proof}

NMR spectroscopy for probing the reactivity and classification of potential skin sensitizers. Chem Res Toxicol 28:1704-1714. https://doi.org/10.1021/acs. chemrestox.5b00098

34. Avonto C, Chittiboyina AG, Rua D, Khan IA (2015) A fluorescence high throughput screening method for the detection of reactive electrophiles as potential skin sensitizers. Toxicol Appl Pharmacol 289:177-184. https://doi.org/10.1016/j.taap.2015.09.027

35. de Groot AC, Schmidt E (2016) Tea tree oil. In: Essential oils. Contact allergy and chemical composition. CRC Press, Taylor \& Francis Group, Boca Raton, pp 809-824

36. Scientific Committee on Consumer Products (2008) Opinion en tea tree oil, SCCP/1155/08

37. Aptula A, Patlewicz G, Roberts D (2005) Skin sensitization: reaction mechanistic applicability domains for structure-activity relationships. Chem Res Toxicol 18:1420-1426. https://doi.org/10.1021/tx050075m

38. Karlberg A-T, Bergstrom MA, Borje A, Luthman K, Nilsson JL (2008) Allergic contact dermatitisformation, structural requirements, and reactivity of skin sensitizers. Chem Res Toxicol 21:53-69. https:// doi.org/10.1021/tx7002239

39. Avonto C, Chittiboyina AG, Wang M, Vasquez Y, Rua D, Khan IA (2016) In chemico evaluation of tea tree essential oils as skin sensitizers: impact of the chemical composition on aging and generation of reactive species. Chem Res Toxicol 29:1108-1117. https:// doi.org/10.1021/acs.chemrestox.5b00530

40. Mori HM, Iwahashi H (2013) Detection and identification of 1-methylethyl and methyl radicals generated by irradiating tea tree (Melaleuca alternifolia) oil with vis- 905 ible light $(436 \mathrm{~nm})$ in the presence of flavine mononu- 906 cleotide and ferrous ion. Free Radic Res 47:657-663. 907 https://doi.org/10.3109/10715762.2013.812785 908

41. Boche J, Runquist O (1968) Kinetics of the thermal 909 rearrangement of ascaridole. J Org Chem 33:4285-4286. 910 https://doi.org/10.1021/jo01275a067 911

42. Christoffers WA, Blömeke B, Coenraads P-J, 912 Schuttelar M-LA (2013) Co-sensitization to ascaridole 913 and tea tree oil. Contact Dermatitis 69:181-191. 914 https://oi.org/10.1111/cod.12086 915

43. Rudzki E, Rapiejko P, Rebandel P (2003) Occupational 916 contact dermatitis, with asthma and rhinitis, from camo- 917 mile in a cosmetician also with contact urticaria from both 918 camomile and lime flowers. Contact Dermatitis 49:162. 919 https://doi.org/10.1111/j.0105-1873.2003.0185e.x 920

44. Avonto C, Rua D, Lasonkar PB, Chittiboyina AG, Khan 921 IA (2017) Identification of a compound isolated from 922 German chamomile (Matricaria chamomilla) with der- 923 mal sensitization potential. Toxicol Appl Pharmacol 924 318:16-22. https://doi.org/10.1016/j.taap.2017.01.009 925

45. Hansen L, Hammershøy O, Boll PM (1986) Allergic 926 contact dermatitis from falcarinol isolated from Schef- 927 flera arboricola. Contact Dermatitis 14:91-93. https:// 928 doi.org/10.1111/j.1600-0536.1986.tb01167.x 929

46. Avonto C, Chittiboyina AG, Sadrieh N, Vukmanovic S, 930 Khan IA (2018) In chemico skin sensitization risk 931 assessment of botanical ingredients. J Appl Toxicol 932 38:1047-1053. https://doi.org/10.1002/jat.3614 933 


\section{Author's Proof}

Index Terms:

Bioassay-guided fractionation 3-4, 6-7,

12

Chamomile plant extract $10-12$

Chemical reactivity 2, 8-12

Direct peptide reactivity assay (DPRA)

2-3

Fluorescence trapping 12

Fragrance mix I (FMI) 3, 6

Gas chromatography-mass spectrometry

(GC-MS) 4, 6, 9

High throughput screening-DCYA (HTS-

DCYA) 8-10, 12

Human cell line activation test (h-CLAT)

2

In chemico methods $8-12$

International Fragrance Association

(IFRA) 6

In vitro assays $10-12$

KeratinoSensTM assay 2, 10

Mass spectrometry (MS) 3

NMR-dansyl cysteamine (NMR-DCYA)

8,10

Nuclear magnetic resonance (NMR) 3,

$8-10$

Oak moss absolute 5-6, 12

Repeated open application test (ROAT) 3,

5,7

Scientific Committee on Consumer

Products (SCCP) 6

Structure-activity relationships (SARs)

4-8

Tea tree oil (TTO) 8-10

Ultra-high performance liquid chroma-

tography coupled with diode array

detection and mass spectrometry

(UHPLC-DAD-MS) 9 


\section{Author's Proof}

\section{Author Queries}

Chapter No.: 5-1 27762_0_En

\begin{tabular}{|c|c|c|}
\hline Query Refs. & Details Required & Author's response \\
\hline AU1 & $\begin{array}{l}\text { Please be aware that your name and affiliation and if } \\
\text { applicable those of you co-author(s) will be published as } \\
\text { presented in this proof. If you want to make any } \\
\text { changes, please correct the details now. Note that } \\
\text { corrections after publication will no longer be possible. }\end{array}$ & $\begin{array}{l}\text { Add after Institut de Chimie: } \\
\text { CNRS UMR } 7177\end{array}$ \\
\hline AU2 & $\begin{array}{l}\text { Please check if all occurrences of "oak moss" should be } \\
\text { changed to "oakmoss." }\end{array}$ & It is correct \\
\hline AU3 & $\begin{array}{l}\text { Please check if edit to sentence starting "And among } \\
\text { them..." is okay. }\end{array}$ & It is correct \\
\hline AU4 & $\begin{array}{l}\text { Please check if edit to sentence starting "The present } \\
\text { chapter..." is okay. }\end{array}$ & It is correct \\
\hline AU5 & $\begin{array}{l}\text { Please check if edit to sentence starting "One patient } \\
\text { was..." is okay }\end{array}$ & It is correct \\
\hline AU6 & $\begin{array}{l}\text { Please check if edit to sentence starting "Because of } \\
\text { the..." is okay. }\end{array}$ & It is correct \\
\hline
\end{tabular}

Note:

If you are using material from other works please make sure that you have obtained the necessary permission from the copyright holders and that references to the original publications are included. 